\title{
EARLY DEVELOPMENTAL EFFECTS OF SEPARATE OR COMBINED PERINATAL EXPOSURE TO METHYLMERCURY (MeHg) AND 2,2',4,4',5,5'-HEXACHLOROBIPHENYL (PCB 153) IN THE RAT
}

\author{
KRYSTYNA SITAREK and SŁAWOMIR GRALEWICZ \\ Nofer Institute of Occupational Medicine, Łódź, Poland \\ Department of Toxicology and Carcinogenesis
}

\begin{abstract}
Objectives: Methylmercury (MeHg) and polychlorinated biphenyls (PCBs) are ubiquitous and persistent environmental pollutants and food contaminants. Both are neurotoxic, especially for the developing nervous system. Material and Methods: Female rats were exposed from day 7 of pregnancy up to day 21 after the delivery to $\mathrm{MeHg}$ in drinking water, PCB 153 per os or $\mathrm{MeHg}+\mathrm{PCB} 153$. Assessment of the exposure effects in mothers included food and water intake, body weight and reproduction success. Assessment of the progeny comprised determination of body weight, time of pinna detachment, eye opening, incisor eruption, and the negative geotaxis, grip strength and righting reflex. Results: The following effects of the exposures were observed: A) MeHg: $0.5 \mathrm{mg} / \mathrm{kg} / \mathrm{day}$ — no effect on maternal health status and reproduction. In the progeny: faster incisor eruption and hastened negative geotaxis development. $\mathrm{MeHg} 2.0 \mathrm{mg} / \mathrm{kg} / \mathrm{day}$ : In mothers: signs of MeHg toxicity (reduced food intake and body weight, ataxia) during lactation. In the progeny: reduced rate of body weight increase, accelerated incisor eruption but delayed development of the righting reflex. B) PCB 153 exposure: $1.0 \mathrm{mg} / \mathrm{kg} / \mathrm{day}$ : no effect on maternal health status, reproduction success or morphological and physical development of the progeny; $5.0 \mathrm{mg} / \mathrm{kg} / \mathrm{day}$ : no effect on maternal health status and reproduction. In the progeny: accelerated growth in females, faster pinna detachment and incisor eruption but delayed development of the grip strength. C) MeHg+PCB153 exposure: none overt effect was noted in mothers or in their progeny. Conclusion: The results confirm the ability of a low level perinatal exposure to $\mathrm{MeHg}$ or PCB 153 to affect the early development in the rat. They have not provided, however, an evidence of a synergistic interaction of these contaminants. To the contrary, the results suggest that, at least under the conditions prevailing in the present study, MeHg and PCB 153 interact antagonistically.
\end{abstract}

Key words:

Methylmercury, Polychlorinated biphenyls, PCB 153, Perinatal exposure, Rat

\section{INTRODUCTION}

Fish and other aquatic organisms are important source of dietary proteins for many human populations. Fish, especially fat fish, are also rich in long chain polyunsaturated fatty acids (omega 3 ), which are necessary for the optimum development and functioning of the cardiovascular and nervous systems. Fish meat, however, is contaminated with methylmercury $(\mathrm{MeHg})$, a potent neurotoxin [1-3]. The MeHg present in fish is a product of bacterial methylation of inorganic mercury compounds. In aquatic systems, it accumulates and biomagnifies in successive steps of the food chain. The well known Minamata and Niigata epidemic outbreaks in Japan [4] have raised the awareness of the health risk resulting from consumption of fish

The study was performed under the "DEVNERTOX" project supported by the European Commission, Contract No. 6PR/03/506143, and The Nofer Institute of Occupational Medicine, Łódź, Scientific Research Program for 2003-2005, Project No. IMP 1.19.

Received: March 16, 2009. Accepted: May 21, 2009.

Address reprint requests to K. Sitarek, Department of Toxicology and Carcinogenesis, Nofer Institute of Occupational Medicine, św. Teresy 8, 91-348 Łódź, Poland (e-mail: ksitarek@imp.lodz.pl). 
(and shellfish) from water basins polluted with industrial wastes containing mercury. In samples of fish from the Minamata Bay the concentration of $\mathrm{MeHg}$ could be as high as $50 \mathrm{ppm}$. In most ocean, sea or fresh water fish species, however, it rarely exceeds $1.0 \mathrm{ppm}[5,6]$. The question is whether, at such a low concentration, $\mathrm{MeHg}$ poses a health threat for fish consumers. So far, evidence of harmful effects of fish consumption for the adult population is lacking. To the contrary, most of the existing evidence suggests beneficial health effects of fish intake[7-12].

There are, however, some reasons for concern. The sensitivity of the nervous system to toxic insults is the highest during development [13]. Being a lipophilic substance, $\mathrm{MeHg}$ crosses easily the biological barriers, including the placenta. Thus, it is likely that maternal fish intake-related $\mathrm{MeHg}$ exposure during pregnancy at levels safe for mothers may affect adversely the developing nervous system of the foetus. This possibility is supported by data from studies of the victims of the mass $\mathrm{MeHg}$ poisonings in Japan [4] and Iraq [14,15]. On the other hand, however, epidemiological studies of children from populations of high fish consumption appear to be inconclusive or contradictory [16]. Particular attention is being paid to the studies performed on two large cohorts of children, the Faroe Island and the Seychelles cohorts. Results obtained in the Faroese cohort indicated MeHg-related deficits in some neurological and cognitive functions, as well $\mathrm{MeHg}$-associated alterations in cardiac autonomic activity $[17,18]$. Studies on the Seychelles cohort revealed no abnormalities [19-21]. Measurements of the $\mathrm{Hg}$ concentration in maternal hair showed that the cohorts did not differ in the level of $\mathrm{MeHg}$ exposure during the intrauterine life [22,23]. According to some authors, the discrepancies between the results of the Faroe and the Seychelles cohorts may be due to some differences in the diet, namely a contribution of whale blubber in the diet of mothers in the Faroe Islands. Whale blubber is contaminated by polychlorinated biphenyls (PCBs) $[24,25]$.

Like $\mathrm{MeHg}$, PCBs are also ubiquitous environmental pollutants and the nervous system is one of the main targets of their toxic activity [26-30]. They were found in the Faroese samples of cord tissue, serum and breast milk, but not in serum from the subjects of the Seychelles study [17,31]. It has been shown in some in vitro studies that PCB and $\mathrm{MeHg}$ may interact in inducing toxicity and that, depending on the concentrations of these compounds in the medium, this interaction may be either synergistic or antagonistic $[32,33]$. Based on the above, some authors presume that the deficits found in children from the Faroe cohort might result from a synergistic action of $\mathrm{MeHg}$ and $\mathrm{PCB}$ to which they were exposed in utero, via maternal blood, and during infancy, via maternal milk [23,34-36]. Validity of the above assumption was tested in several in vivo studies on laboratory animals [37-39]. They did not provide, however, confirmatory evidence of a synergistic $\mathrm{MeHg}$ and PCB interaction.

The problem of the MeHg and PCB interaction was the subject of the DENVERTOX project supported by the European Commission (6PR/03/506143/UE). The study described in the present report was a part of one of the workpackages (WP7) of that project. In this study we tried to establish whether and how the effects of combined perinatal exposure to $\mathrm{MeHg}$ and a selected $\mathrm{PCB}$ congener differ from the effects of separate exposures to these compounds. The selected PCB congener was PCB 153 (2,2',4,4',5,5'-hexachlorobiphenyl). Out of the 209 PCB congeners, PCB 153, is the congener detected in biological samples most frequently and at highest proportions [40].

\section{MATERIALS AND METHODS}

\section{Study design}

The study comprised three separate experiments. Experiment I was concerned with the effects of perinatal exposure to methylmercury $(\mathrm{MeHg})$, experiment II studied the effects of exposure to PCB 153, while experiment III was intended to test the effects of combined exposure to $\mathrm{MeHg}$ and PCB 153. Each experiment was composed of four parts, of which the first dealt with the effects of exposure observed during the preweaning period of life. The remaining three parts dealt with the effects seen in adulthood and dealt with the levels of catecholamines in the brain, sensitivity to psychostimulants and susceptibility to psychostimulant sensitization, and neurobehavioral 
functions. This report contains results obtained in the first part.

\section{Ethical issues}

In all the experiments, the Polish law on the protection of animals was observed (Animal Protection Act of August 21, 1997. Off J Law 1997;111:3445-53 (in Polish). The study design was approved by the Local Ethic Committee in Lodz (Opinion No. Ł/BD/187, Issue date: December 1, 2003).

\section{Animals}

All experiments were performed on rats, white WISTARS. The parental material was obtained from the Institute's breeding colony and consisted of 98 virgin females 10-week old and 98 males 12-week old. Upon arrival, the animals were housed in plastic rat cages $(40 \times 30 \times 25 \mathrm{~cm})$ in standard laboratory conditions. The maternal cohort in experiment I (exposure to $\mathrm{MeHg}$ ) consisted of 35 females separated into three groups; a control group $(\mathrm{n}=12)$, a low dose group $(\mathrm{n}=12)$ and a high dose group $(\mathrm{n}=11)$. In experiment II (exposure to PCB153), the maternal cohort consisted of 36 females (11 in the control group,12 in the low dose group, and 13 females in the high dose group). In experiment III (combined exposure to $\mathrm{MeHg}$ and PCB 153) the maternal cohort consisted of 27 females separated into two groups: the control group $(n=14)$ and the exposed group $(n=13)$.

\section{Mating and conception control}

After a two-week acclimation in the laboratory the animals were mated. Vaginal smears were taken daily between 8 a.m. and 9 a.m. from mated females. On the day when spermatozoa in the vaginal smear were found, the female was weighted and transferred back to its home cage and this day was regarded as the first day of gestation (GD1).

\section{Exposure and exposure control}

In all cases the exposure was carried out from the 7 day of gestation (GD7) until the postnatal day 21 (PND 21). The compounds used in the present study were: methylmercury chloride $\left(\mathrm{CH}_{3} \mathrm{HgCl}\right)-\mathrm{CAS}$ No. 115-09-3, purity: > 98\%, and PCB 153 (2,2',4,4',5,5'-hexachlorobiphenyl)
Cat No. 35602, CAS No 35065-27-1, purity > 99\%. Both were purchased from Sigma-Aldrich.

\section{Exposure to $\mathrm{MeHg}$}

A stock solution was prepared by diluting $100 \mathrm{mg} \mathrm{MeHgCl}$ in $1.0 \mathrm{ml}$ of dimethyl sulfoxide (DMSO). Using the stock solution, the tap water provided to rats was adulterated with $\mathrm{MeHg}$ and DMSO. The water provided to control rats contained DMSO only at concentration matching the concentration in the water drank by the exposed dams. Based on the measurements of daily fluid intake and body weight, the $\mathrm{MeHg}$ concentration in the drinking water was adjusted so as to attain, as close as possible, the expected daily $\mathrm{MeHg}$ intake, i.e. $0.5 \mathrm{mg} / \mathrm{kg}$ b.w. in the low dose group and $2.0 \mathrm{mg} / \mathrm{kg}$ b.w. in the high dose group. The level of the low dose was based on data showing that at this exposure level, the mercury concentration in newborn rats was comparable to that found in human infants from populations with high dietary fish consumption [41,42].

\section{Exposure to PCB 153}

PCB was administered intragastrically by gavage in daily doses of $1.0 \mathrm{mg} / \mathrm{kg}$ b.w. (low dose group) or $5.0 \mathrm{mg} / \mathrm{kg}$ b.w. (high dose group). For this purpose, PCB was dissolved in corn oil to appropriate concentration and administered at $2.0 \mathrm{ml} / \mathrm{kg}$ b.w. Control animals received $2.0 \mathrm{ml} / \mathrm{kg}$ of unadulterated corn oil via the same route.

\section{Exposure to $\mathrm{MeHg}+\mathrm{PCB} 153$}

In the experiment on the effects of the joint exposure $\mathrm{MeHg}$ was administered in drinking water (daily $\mathrm{MeHg}$ intake $\approx 0.5 \mathrm{mg} / \mathrm{kg}$ b.w.), and PCB 153, diluted in corn oil, was administered by gavage at $5.0 \mathrm{mg} / \mathrm{kg}$ b.w./day. Animals of the control group drank unadulterated water and received intragastrically corn oil.

\section{Observations made during pregnancy}

During pregnancy, body weight, food and fluid consumption were measured. The females were checked every morning and the day the pups were first observed was defined as postnatal day 1 (PND 1). The cage bedding was changed every day. 


\section{Assessment of the reproduction success}

On PND 1, the dead and alive pups were counted, weighted and their sex was determined. Then, the litters were culled to eight animals each and balanced for sex (4 females and 4 males) to the extent possible.

\section{Assessment of the offspring's morphological development}

From birth (PND 1) to weaning (PND 21) the offspring was assessed for the general appearance, litter weight, mean pup weight and mortality. Additionally, the following developmental landmarks were recorded: pinna detachment, incisor eruption, and eye opening.

\section{Assessment of the offspring's physical development}

To assess the physical development, the following competencies were tested: negative geotaxis, grip strength (the forepaw suspension test), and the righting reflex (the freefall righting test). The testing was performed as suggested by Overmann et al. [43].

\section{Negative geotaxis}

The rat was placed head downward longitudinally along a starting line drawn on a plywood plane $(45 \times 45 \mathrm{~cm})$ inclined 20 from horizontal. The adopted response criterion was a $135^{\circ}$ upward turn. The latency of the turn and the number of unsuccessful trials were recorded. Individual scores were averaged to yield one daily performance value for males and females within each litter. This test was repeated daily between 7-11 PND.

\section{Forepaw suspension test}

In this test the pup is held by its waist with its forepaws touching a taut wire extending horizontally $25 \mathrm{~cm}$ above a thick foam-rubber pad. Then it is released and if it grasps the wire and remains suspended for at least two seconds, the trial is considered successful. If the pup drops down before 2 secs, the trial is considered aborted and a new trial is initiated. The mean suspension duration of two successful trials was used as the daily performance score for each pup. This test was repeated daily between 12-15 PND.

\section{Free-fall air righting test}

In this test the pups were dropped, back downwards, from a height of $35 \mathrm{~cm}$ onto a thick foam-rubber pad. Each pup was given three trials a day, with intertrial interval of 10-15 secs, and the number of trials in which the rat turned mid-air to land on four feet on the foam-rubber pad was recorded. This test was performed daily between PND 14 and PND 18. Successful performance in three successive trials was regarded as a criterion and conclusion of the testing.

\section{Statistics}

A two-way ANOVA (groups $x$ measurements) for repeated measures was employed for statistical assessment of the differences. When a significant interaction was found, it was followed by one-way ANOVA and Tukey's test for pairwise comparisons [44]. Differences were regarded as significant when the probability of the null hypothesis was $5 \%$ or less.

\section{RESULTS}

\section{Experiment I: Effects of exposure to methylmercury}

Maternal health status and reproduction outcome During pregnancy the groups did not differ in water and food intake (not shown), and in the rate of the body mass increase (Fig. 1). At about PND 9, in the high dose group,

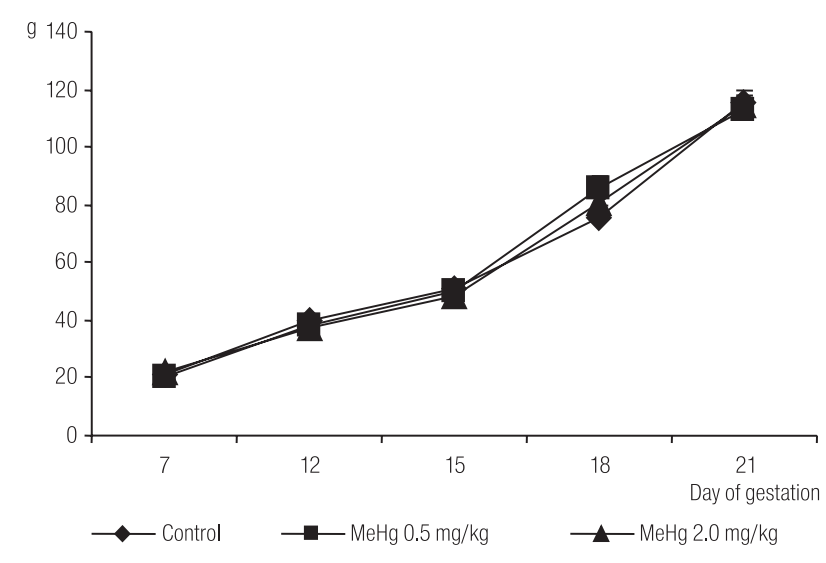

Data points represent mean values \pm SE with 11-12 females in each group.

Fig. 1. Effects of MeHg exposure. Body weight gain (g) during pregnancy. 

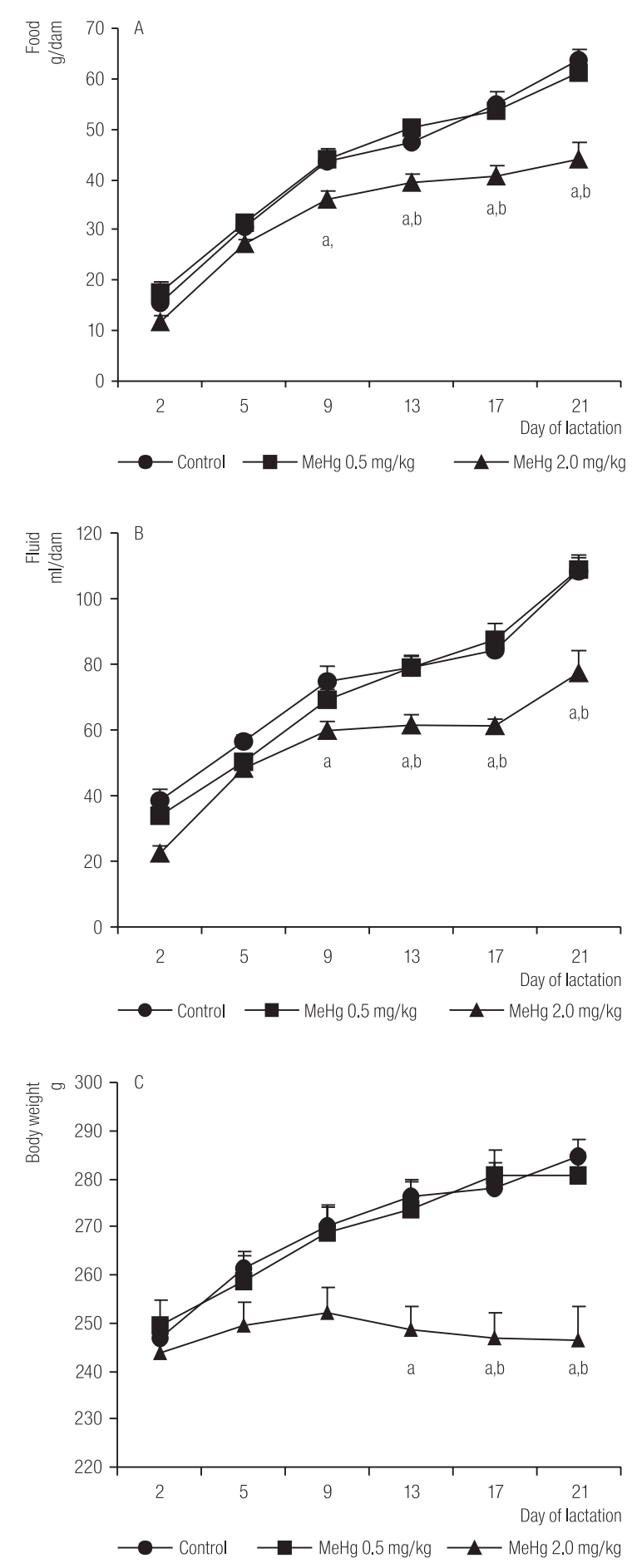

$\mathrm{a}-$ significantly $(\mathrm{p}<0.05)$ different from the control group. $\mathrm{b}$ - significantly different from the $0.5 \mathrm{mg} / \mathrm{kg}$ group.

Fig 2. Effects of MeHg exposure. The data show daily food (A) and water (B) intake, and body weight (C) changes during lactation in dams of the control, low dose, and high dose groups.

the increase in the daily food and water consumption was retarded and the body weight declined. Moreover, in 6 dams of this group, anxiety and ataxia was observed at the end of the breast feeding period. The low dose group did not differ from the control group in the level of food and water consumption and body weight gain during lactation (Fig. 2).

There were no significant differences between groups in the number of pups per litter, male/female ratio, or the number of stillbirths. In the high dose group, however, the values of the viability index (i.e. percent of pups surviving beyond PND 4), and the lactation index (i.e. percent of pups surviving up to weaning, i.e. PND 21) were notably lower (Table 1).

Effects of maternal $\mathrm{MeHg}$ exposure in the offspring Body weight

There were no differences between the progeny of the control and $\mathrm{MeHg}$ exposed groups in body weight
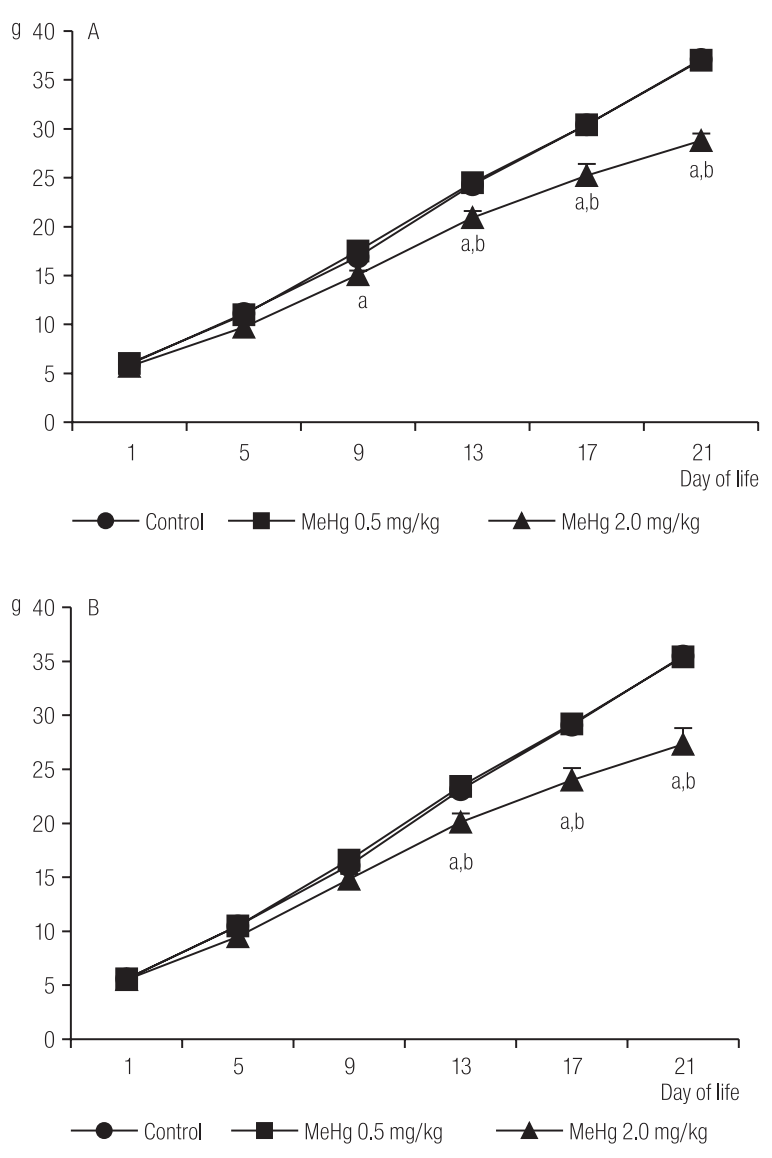

a - significantly different $(\mathrm{p}<0.05)$ from the control group. $\mathrm{b}$ - significantly different from the low dose $(0.5 \mathrm{mg} \mathrm{MeHg})$ group. Data points represent mean values \pm SE with $11-12$ litters in each group.

Fig 3. Effects of perinatal MeHg exposure. The data show changes in body weight in the male (A) and female (B) progeny from PND 1 to PND 21. 
at PND 1. In successive days, however, in pups of the high dose group, males and females, body weight increases were smaller than in pups of the remaining groups (Fig. 3).

\section{Pinna detachment}

Pups of the exposed groups, males and females, did not differ from their control counterparts in the time of pinna detachment. By PND 4, 100\% of pups in all groups had their pinna detached (data not shown).

\section{Incisor eruption}

In male as well as female pups of the high dose group, incisor eruption was significantly hastened compared to the progeny of the control group. In pups of the low dose group, this effect was also present but was less pronounced (Fig. 4).

\section{Eye opening}

Pups born to MeHg exposed mothers of both groups did not differ from control pups in the time of eye opening (data not shown).

\section{Negative geotaxis}

Males and females of the low dose group performed significantly better in the negative geotaxis test than their counterparts from the control group. There were no differences in the geotaxis test performance between the control and the high dose group (Fig. 5).
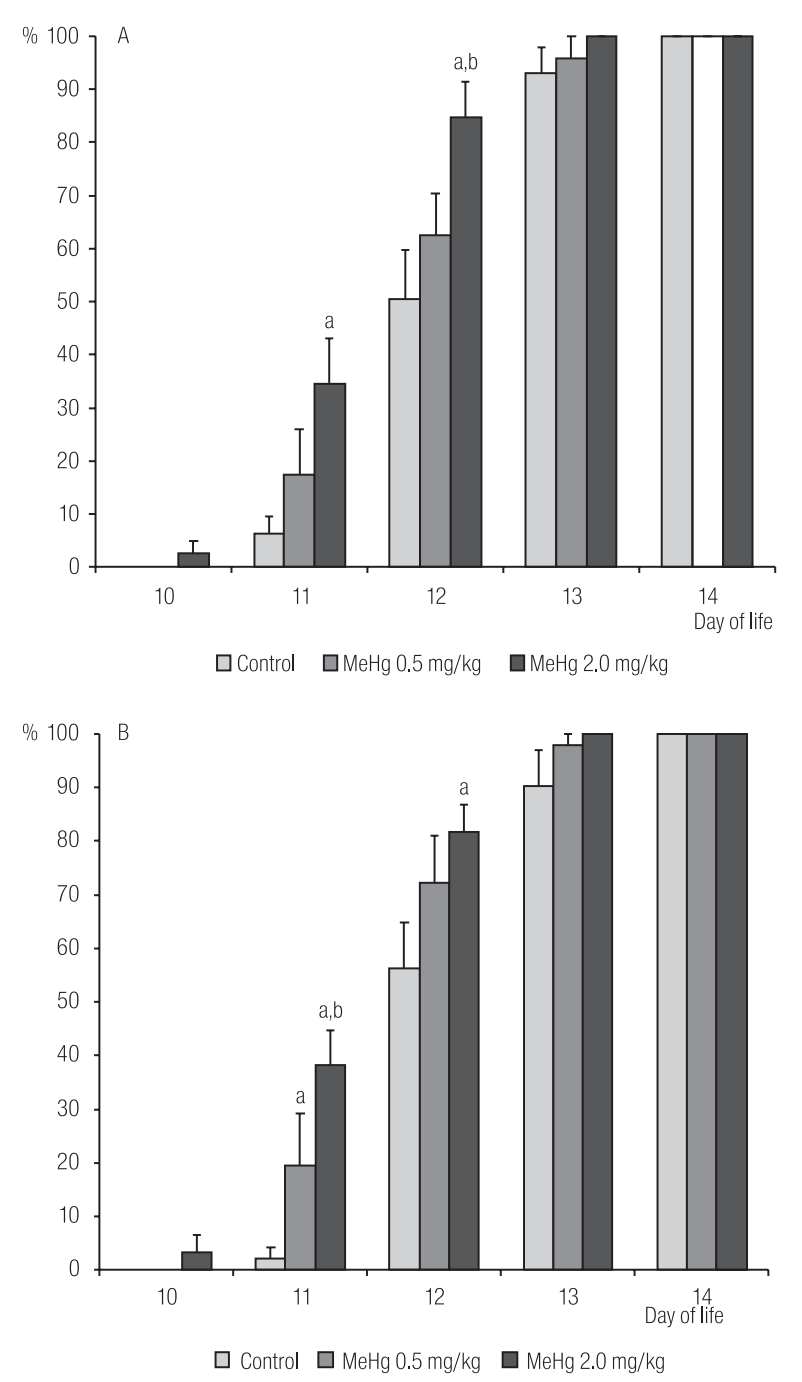

Abbreviations as in Fig. 3.

Data points represent mean values \pm SE with 11-12 litters in each group.

Fig. 4. Effects of MeHg exposure. The diagrams show percentage of offspring males (A) and females (B) with incisors erupted from PND 10 to PND 14.

Table 1. Effects of perinatal exposure to $\mathrm{MeHg}$ - reproduction outcome of $\mathrm{MeHg}$ exposed female rats and viability of their progeny

\begin{tabular}{lcccccccc}
\hline \multirow{2}{*}{$\begin{array}{c}\text { Group of pregnant } \quad \\
\text { females }\end{array}$} & \multicolumn{3}{c}{ Mean number of pups per litter \pm SD } & \multicolumn{4}{c}{ Indices $^{2}$} \\
\cline { 2 - 8 } & female & male & female & male & female & male & female & male \\
\hline $\begin{array}{l}\text { Control } \\
\quad \mathrm{n}=12\end{array}$ & $5.5 \pm 2.0$ & $6.8 \pm 1.7$ & $0.1 \pm 0.3$ & 0 & 95.5 & 98.0 & 93.2 & 96.1 \\
$\begin{array}{l}\mathrm{MeHg} 0.5 \mathrm{mg} / \mathrm{kg} \\
\quad \mathrm{n}=12\end{array}$ & $5.3 \pm 1.8$ & $6.5 \pm 2.3$ & 0 & 0 & 100 & 100 & 97.8 & 100 \\
$\begin{array}{l}\mathrm{MeHg} 2.0 \mathrm{mg} / \mathrm{kg} \\
\mathrm{n}=11\end{array}$ & $5.8 \pm 2.6$ & $5.5 \pm 1.0$ & $0.1 \pm 0.3$ & $0.4 \pm 0.7$ & 87.2 & 91.7 & 79.5 & 81.3 \\
\hline
\end{tabular}

a $\%$ of pups born alive that survived to 4 days.

b $\%$ of pups born alive that survived to 21 days. 

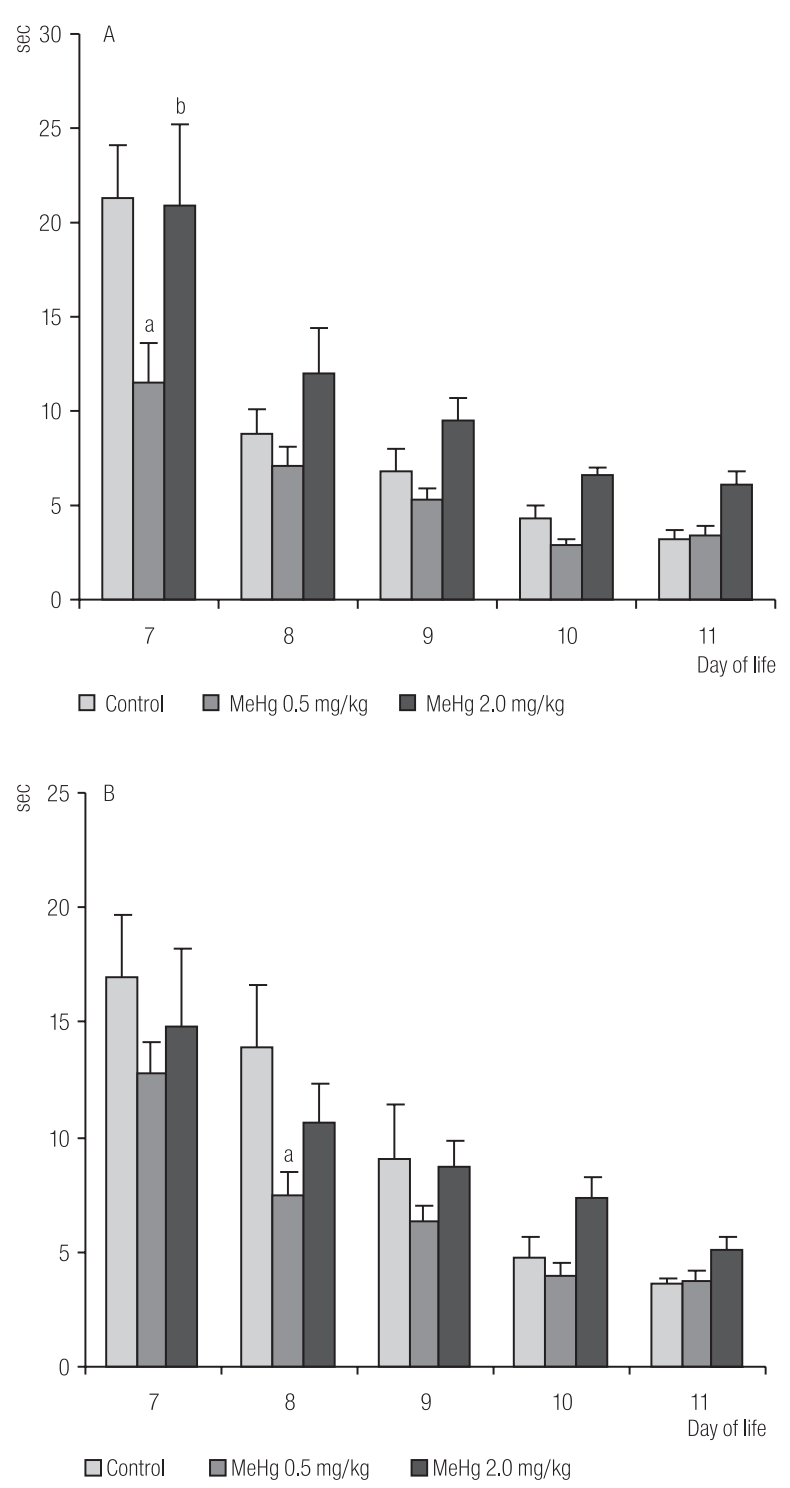

Abbreviations as in Fig. 3.

Data points represent mean values \pm SE with 11-12 litters in each group.

Fig. 5. Effects of MeHg exposure. The diagrams show results of negative geotaxis test (sec) in offspring males (A) and females (B) from PND 7 to PND 11.

\section{Forepaw suspension test}

In all four days of testing, pups of the high dose group were apparently impaired (released the grip sooner) compared to pups of the control group (Fig. 6).

\section{Free fall righting test}

On PND 14-16, in the high dose group the proportion of pups, males and females, showing righting reflex was significantly smaller than in the control group. This difference disappeared by PND 17. On PND 14, also males of the low dose group showed poorer performance than males of the control group. In this case, however, the difference was probably accidental (Fig. 7).

Summary of the effects of the perinatal MeHg exposure Neither low nor high MeHg exposure during gestation and lactation affected significantly reproduction success:

- low level exposure resulted in no adverse developmental effects in the progeny and facilitated negative geotaxis development;

- high level exposure resulted in a slower growth rate of the pups, disturbed the timing of developmental milestones (delayed pinna detachment and hastened
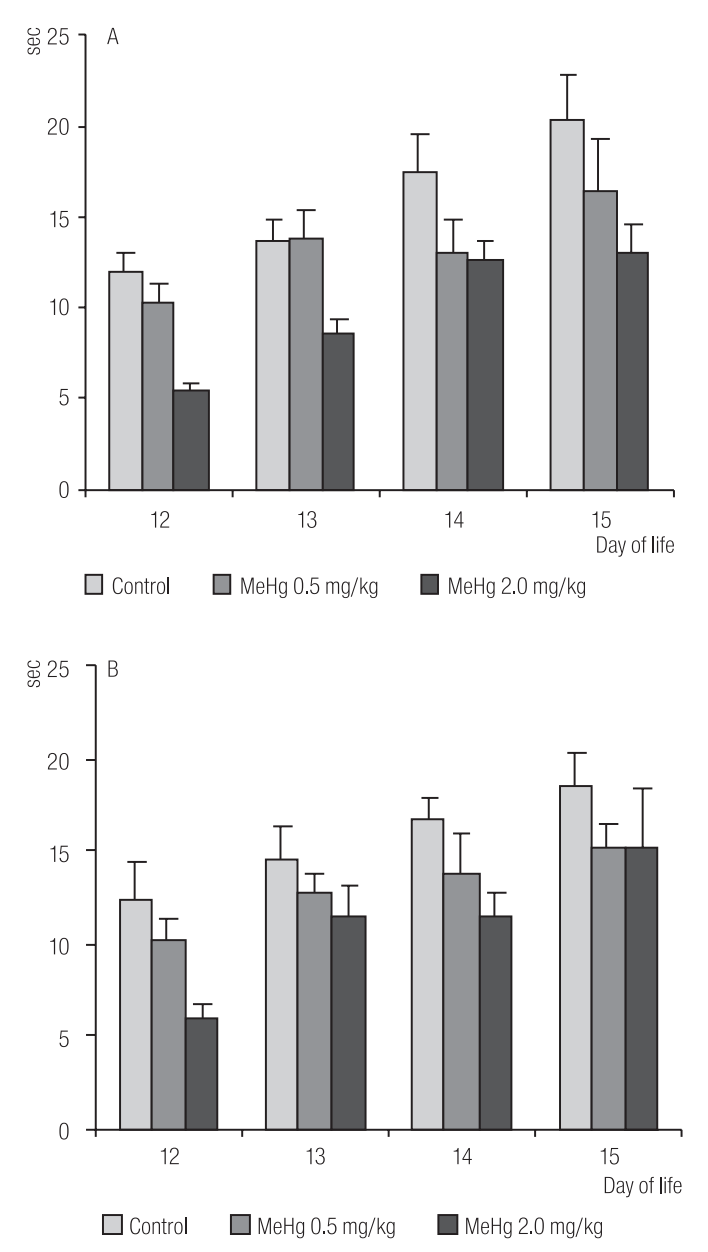

Abbreviations as in Fig. 3.

The bars represent mean of litter mean values \pm SE with 11-12 litters in each group.

Fig. 6. Effects of MeHg exposure. The diagrams show results of forepaw suspension test (sec) in offspring males (A) and females (B) from PND 12 to PND 15. 

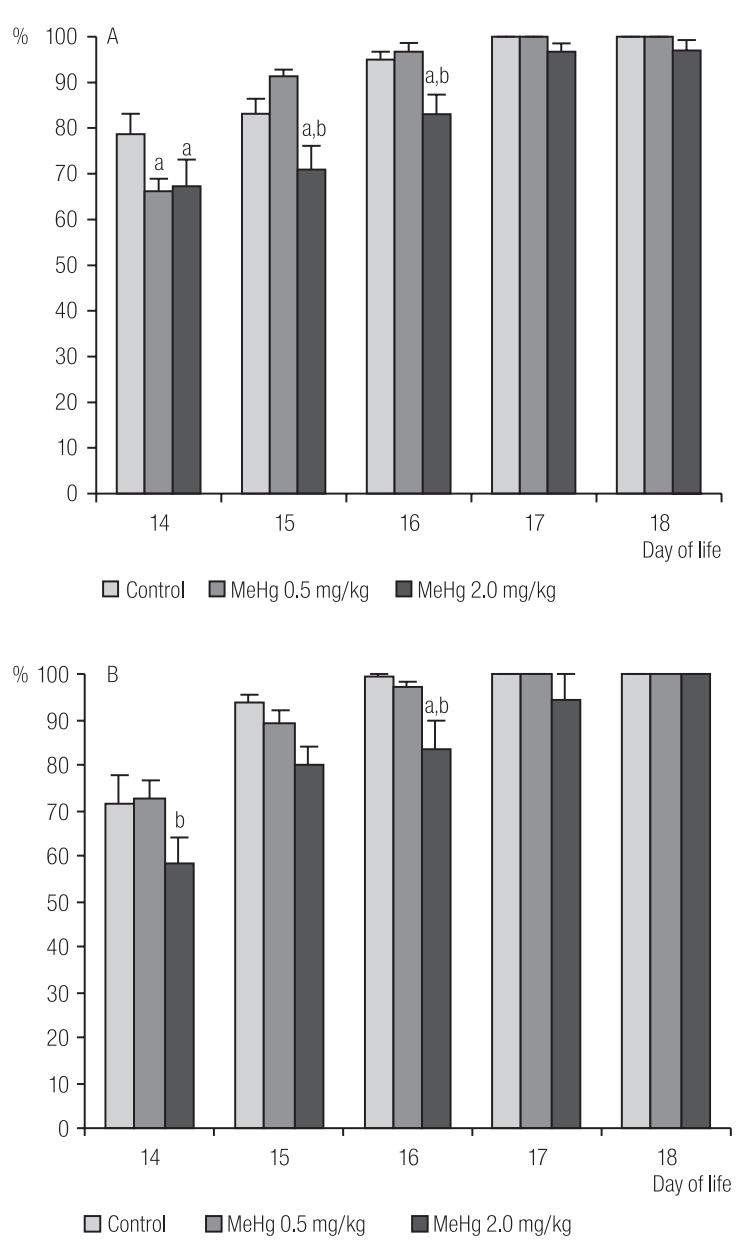

Abbreviations as in Fig. 3.

The bars represent mean of litter mean values \pm SE with 11-12 litters in each group.

Fig. 7. Effects of MeHg exposure. The diagrams show percentage positive reactions in air righting test of offspring males (A) and females (B) from PND 14 to PND 18.

incisor eruption) and delayed physical development (lower rate of muscular strength gain and muscular coordination).

\section{Experiment II: Effects of exposure to PCB 153}

Maternal health status and reproduction outcome

During gestation the groups did not differ in daily food and water intake, body weight and the rate of the body weight gain (data not shown). During lactation the maternal groups did not differ remarkably in water consumption and food intake (data not shown).

There were no differences between the maternal groups in the number of pups per litter. The groups did not differ in the number of stillbirths, the viability index, and the lactation index (data not shown).

Effects of exposure in the offspring

\section{Body weight}

On PND 1 there were no differences between litters of the exposed and the control groups in the mean body weight of female or male pups. In successive days, however, pups of the exposed groups gained weight faster than pups of the control group. At weaning (PND 21) female pups of the high dose group were significantly heavier than control females. In the male progeny the relations between groups were similar as in the females but the differences between groups were less pronounced (Fig. 8.).
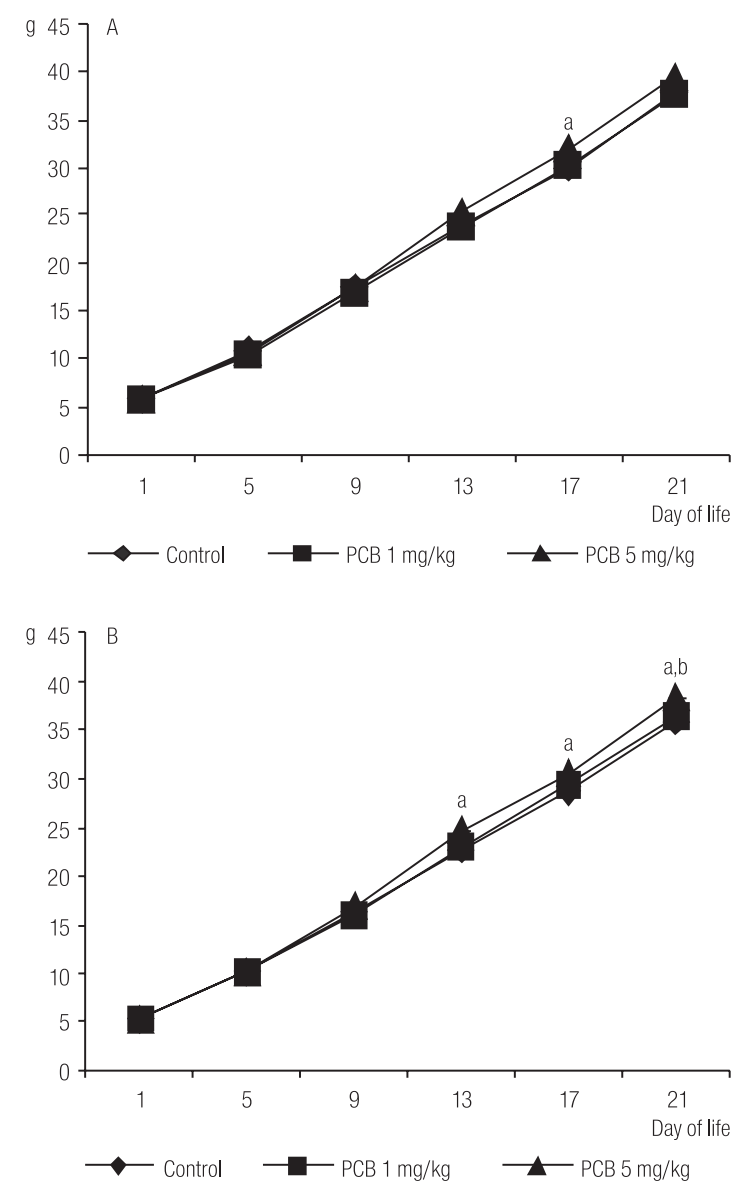

a - significantly different $(p<0.05)$ from the control group. $\mathrm{b}$ - significantly different from the low dose (1.0 $\mathrm{mg} \mathrm{PCB})$ group. Data points represent mean values \pm SE with $11-13$ females in each group.

Fig. 8. Effects of perinatal PCB 153 exposure. The diagrams show changes in body weight in the male (A) and female (B) progeny from PND 1 to PND 21. 

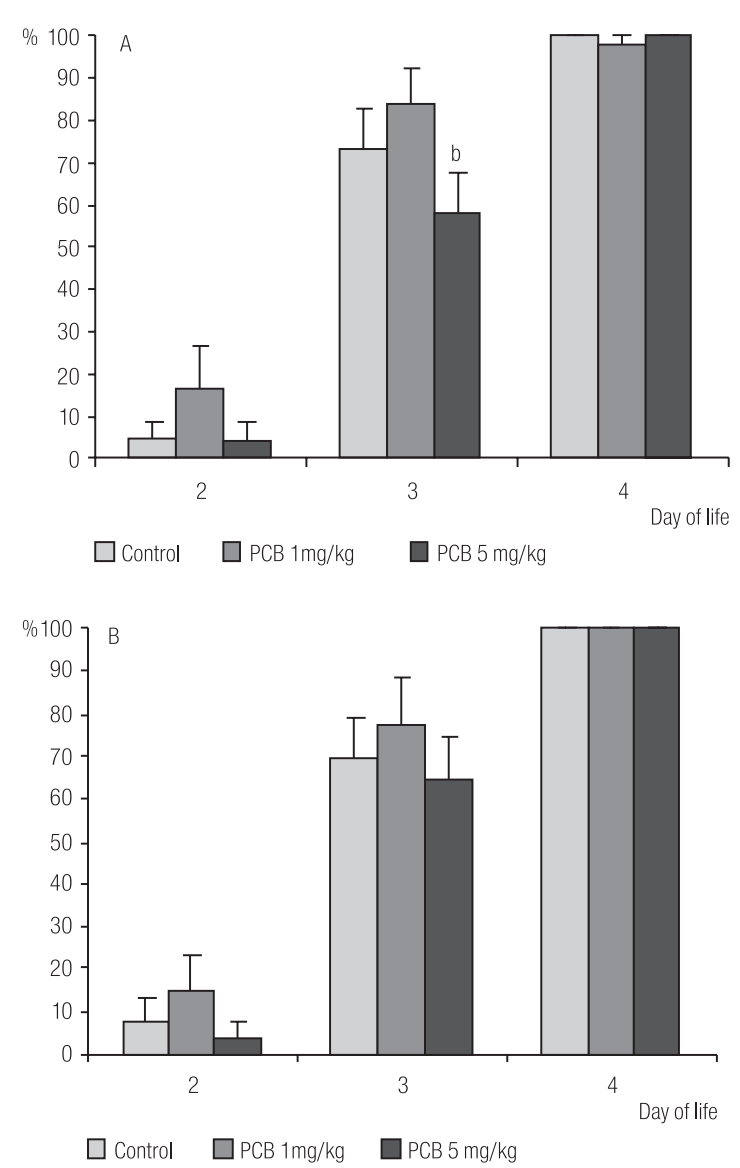

Abbreviations as in Fig. 8.

Data points represent mean values \pm SE with $11-13$ females in each group.

Fig. 9. Effects of perinatal PCB 153 exposure. The diagrams show percentage of offspring males (A) and females (B) with detached pinna from PND 2 to PND 4.

\section{Pinna detachment}

The male and female offspring of the exposed groups did not differ from their counterparts in the control group in the time of pinna detachment. On PND 2 and 3, however, the proportion of pups with detached pinna in the low dose group was notably higher and in the high dose group notably lower than in the control group (Fig. 9).

\section{Incisor eruption}

On PND 12, the proportion of pups with erupted incisors in the male progeny of the low dose group was significantly larger than in the control and in the high dose group. In the female progeny, this proportion was also significantly larger but only in comparison with the high dose group (Fig. 10).

\section{Eye opening}

In the male and in the female progeny there were no differences between groups in the time of eye opening (data not shown).

\section{Negative geotaxis}

In the male as well as in the female progeny there were no significant differences between the control group and the exposed groups in the negative geotaxis test performance (data not shown).

\section{Forepaw suspension}

In all groups, the latency of the grip release increased gradually in successive days but the rate of this increase was not the same in all groups. From the first to the last
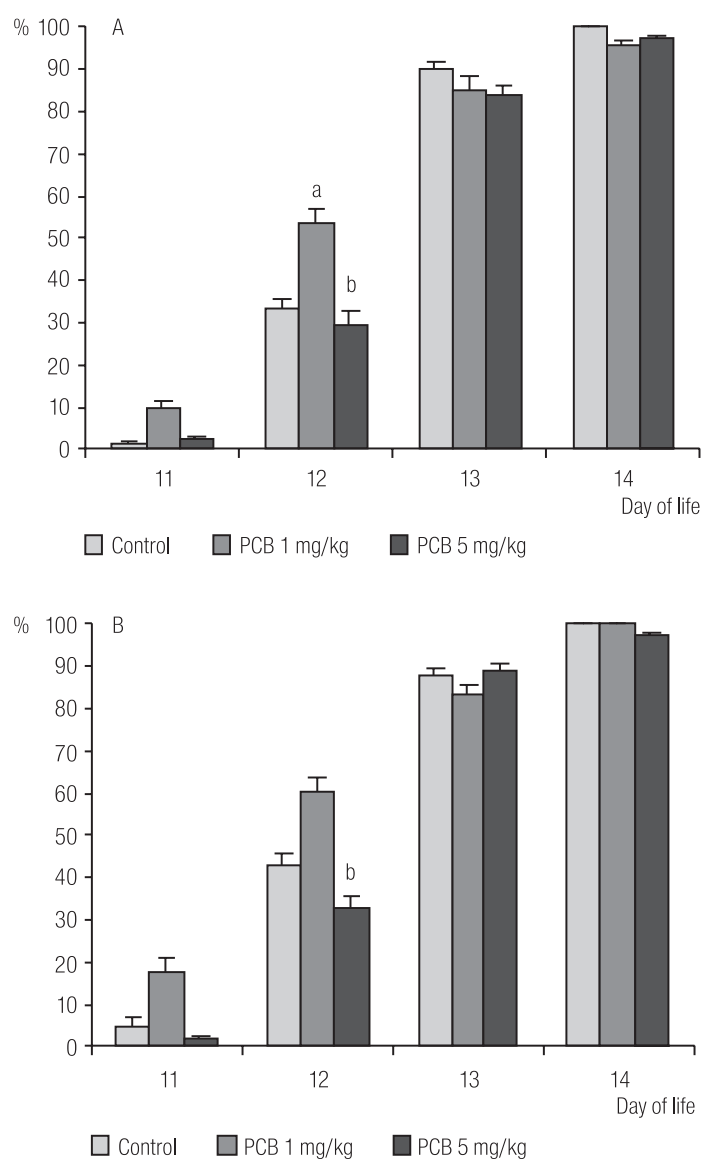

Abbreviations as in Fig. 8.

Data points represent mean values \pm SE with $11-13$ females in each group.

Fig. 10. Effects of perinatal PCB 153 exposure. The diagrams show percentage of offspring males (A) and females (B) with erupted incisors since PND 11 till PND 14. 


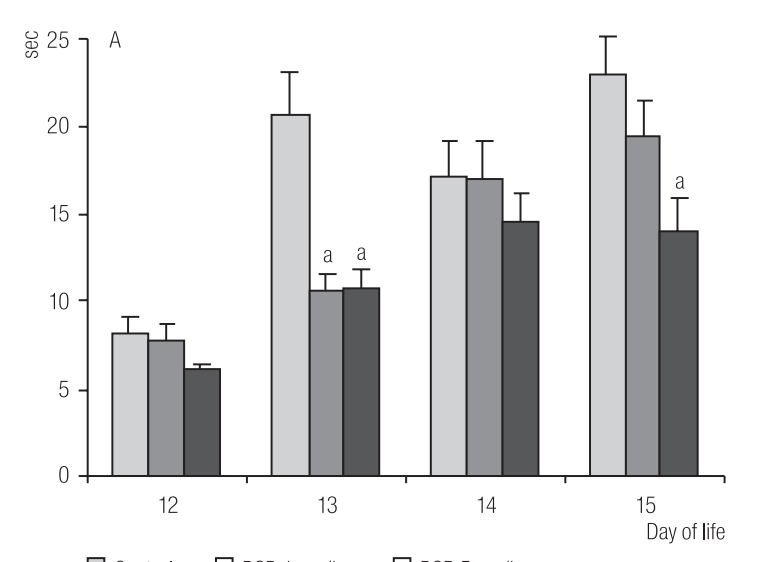

$\square$ Control $\quad \square$ PCB $1 \mathrm{mg} / \mathrm{kg} \quad \square$ PCB $5 \mathrm{mg} / \mathrm{kg}$

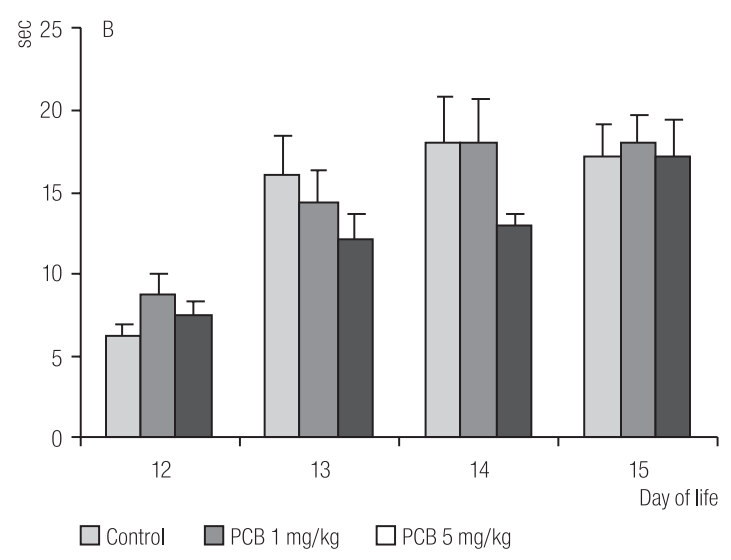

$\mathrm{a}-$ significantly different $(\mathrm{p}<0.05)$ from the control group.

The bars represent mean of litter mean values \pm SE with 11-13 litters in each group.

Fig. 11. Effects of PCB 153 exposure. The diagrams show results of forepaw suspension test (sec) in offspring males (A) and females (B) from PND 12 to PND 15.

day of testing the male progeny of the high dose group showed an impairment in the forepaw suspension test performance. Males of the low dose group did not differ notably from males of the control group. In the female progeny, the groups did not differ in the latency of the grip release in any of the four days of testing (Fig. 11).

\section{Free fall air righting}

No significant differences between groups, males and females, were found (data not shown)

Summary of the effects of the perinatal PCB 153 exposure

Generally, the results of Experiment II indicate:
- no effect of the PCB 153 exposure, low and high alike, on the maternal health status and reproduction success;

- no effect of the low level PCB 153 exposure on the female offspring and growth acceleration in the female and male pups of the high exposure group;

- some functional impairment of the skeletomuscular system in the male progeny of the high dose group (lower muscular strength or endurance).

\section{Experiment III: Effects of combined perinatal exposure to MeHg and PCB 153}

Maternal health status and reproduction outcome

Neither during gestation, nor during lactation did the maternal groups differ in body weight, the daily water and food consumption, and body weight gain (data not shown).

There were no differences between the maternal groups in the number of pups per litter but in the exposed group the proportion of female pups was significantly $(\mathrm{p}<0.05)$ higher than in the control ( 7.2 female and 5.5 male pups per litter in the exposed group and 5.4 female and 6.5 male pups per litter in the control group). The groups did not differ in the number of stillbirths, the value of the viability index or the lactation index.

Effects of MeHg+PCB 153 exposure in the offspring Body weight

From PND 1 to PND 21 there were no differences between the exposed and the control group in the mean body weight of female and male pups (data not shown).

\section{Developmental milestones and physical development}

The offspring of the exposed group, males as well as females, did not differ from the offspring of the control group in the time of pinna detachment, incisor eruption, eye opening and the performance in the negative geotaxis, grip strength (forepaw suspension) and free fall righting tests (data not shown). 
Summary of the effects of the perinatal $\mathrm{MeHg}+\mathrm{PCB} 153$ exposure

Generally, the results indicate that the combined exposure to PCB 153 (5.0 mg/kg/day) and $\mathrm{MeHg}(0.5 \mathrm{mg} / \mathrm{kg} /$ day $)$ during gestation and lactation:

- does not affect the health status and reproduction outcome of mothers,

- results in no noticeable effects of the morphological and physical development of their offspring.

\section{DISCUSSION}

\section{Effects of the MeHg exposure}

In spite of a relatively high interest in the $\mathrm{MeHg}$ toxicity, the number of reports from experimental studies on the early developmental effects of prenatal or perinatal exposure to this neurotoxicant is not large. Moreover, the differences in the dose magnitude, route of exposure, the dosing regime and the experimental endpoints make comparisons difficult. Dietary exposure via drinking water during gestation and lactation at doses of $0.5 \mathrm{mg} / \mathrm{kg} /$ day was used in some studies, including those performed under the DEVNERTOX project [45,46]. Any significant effects on the maternal health status, reproduction success, offspring's body weight at birth and body weight increase from birth to weaning were not reported. In none of these studies, however, the offspring was subjected to a detailed testing. The only report showing data which could be compared with those contained in the present work is the report of Vorhees [47]. In that study, rats received $\mathrm{MeHg}$ at two dosing levels: 2.0 or $6.0 \mathrm{mg} / \mathrm{kg}$ b.w. from GD6 to GD9. Thus, the cumulated $\mathrm{MeHg}$ doses received by these dams was comparable with doses received during gestation by the dams of the low and high dose groups of the present study.

A comparison of our and the Vorhees data shows considerable similarity in the effect of exposure. In both studies:

- the number of pups per litter, gender proportion in litters and pup viability were not affected by the exposure;

- the offspring mortality in the high dose group was slightly increased;
- in the progeny of the high dose group the rate of the body weight increase after birth was reduced (in our study this reduction was stronger);

- the incisor eruption was accelerated (in the Vorhees study this effect was noted in the high dose group only whereas in our it was noted in both groups);

- in the negative geotaxis test the progeny of the low dose group performed better than the controls;

- the development of the righting reflex was delayed in the progeny of the high dose group.

It may also be added that in both studies the profile of the exposure effects in males and females was similar.

The differences relate to:

- effects on the maternal health status during lactation: In the Vorhees's study no effect was observed, whereas in ours signs of toxicity - gait disturbances, reduced food intake and body weight increase - were noted in mothers of the high dose group;

- effect on the offspring's morphological development; in our study, in the progeny of the high exposed group, the growth was retarded, possibly due to the poor health of the mothers.

There is no doubt that the similarities prevail, and thus it is reasonable to regard observations made in the present study as reliable.

\section{Effects of PCB 153 exposure}

PCBs were produced and used as mixtures and therefore the toxicologists' focus is on the health effects of mixtures rather than single congeners. Aroclor 1254 is the industrial PCB mixture which has been studied most intensely. The published data indicate that perinatal exposure to Aroclor 1254 at daily doses of $15 \mathrm{mg} / \mathrm{kg}$ increases offspring's mortality, reduces body growth rate, delays pinna detachment and righting reflex development, and reduces grip strength but accelerates eye opening [4850]. Exposure of shorter duration or at lower doses is ineffective or results in lower body weight at birth and lesser body weight gain [48]. As regards PCB 153, there are only few reports concerning the developmental effects of exposure to this congener. In one of the earliest reports, female rats were exposed to PCB 153 at doses 
of 16 or $64 \mathrm{mg} / \mathrm{kg} /$ day from GD10 to GD16. No adverse effect on the maternal health status or reproduction performance was noted [51].

In another study [52,53] PCB 153 at $5.0 \mathrm{mg} / \mathrm{kg} /$ day was given to rat mothers every second day from PND 3 to PND 13. No signs of maternal toxicity were observed. As regards the progeny, the males of the exposed group weighted slightly less then controls but, generally, the groups did not differ in the rate of body weight gain after birth. The preweaning testing revealed no between-group differences in fur development, pinna detachment, eye opening or righting reflex.

Recently Kobayashi et al. [54] have published data from an experiment in which female rats were exposed to PCB 153 from GD10 to GD16 at 0,16 or $64 \mathrm{mg} / \mathrm{kg} /$ day. Like in the Schantz et al. experiment [51] the exposure resulted in no adverse effect on the health status and reproduction success of mothers. Testing of the progeny included some morphological measures only and an assessment of the hormonal status. Some differences in the morphological measures (body length, body and organ weight) were noted but, generally, they were small and of ambiguous significance. The hormone assays revealed that at age 1 and 3 weeks, plasma T4 levels were lower among the PCB 153 treated groups compared with controls - but differences were significant only for the $64 \mathrm{mg} / \mathrm{kg}$ group. The authors conclude that in utero exposure to PCB 153 decreases neonatal thyroid hormone levels in rat offspring to some extent without affecting somatic growth [54].

Similar exposure regime as that in the present study was also employed in other studies performed under the DEVNERTOX project. In one of these studies [45] PCB 153 was administered in diet at daily doses of $5.0 \mathrm{mg} /$ $\mathrm{kg}$, and in the second one [46] at $1.0 \mathrm{mg} / \mathrm{kg}$. None of these studies revealed adverse effects of PCB 153 on maternal health and reproduction. The authors did not mention any adverse effect on the offspring development from birth to weaning. It appears from the above that, as regards the effects of the PCB 153 exposure on mothers' health and reproduction, our results are concordant with those reported by authors quoted above. They indicate no adverse effects of exposure at doses of 1 or $5 \mathrm{mg} / \mathrm{kg} /$ day during gestation and lactation. As regards the progeny, the situation is more complicated. Because it is not possible to confront our observations with data by other authors, we have no choice but to accept our results at face value. They suggest that perinatal exposure to PCB 153 at daily doses of $1.0 \mathrm{mg} / \mathrm{kg}$ exerts no marked effect on the offspring's development. However, exposure at $5.0 \mathrm{mg} / \mathrm{kg}$ results in a faster body weight gain of the female progeny, and retarded development of muscular strength and endurance in males. The latter effect is not surprising; reduced grip strength was also reported after exposure to Aroclor 1254 or a PCB/organochlorine mixtures [49]. The faster body weight gain, however, is unexpected; a reduced body growth rate would be more likely $[49,50]$. Nonetheless, from the tables included in the Kobayashi et al. report [54] one may easily note that the progeny of the $16 \mathrm{mg} / \mathrm{kg}$ PCB 153 group was heavier compared to control.

\section{Effects of combined exposure to $\mathrm{MeHg}$ and PCB 153}

Table 2 shows the profile of effects produced by the separate exposure to $\mathrm{MeHg}$ or $\mathrm{PCB} 153$, and the combined $\mathrm{MeHg}+\mathrm{PCB} 153$ exposure. If the co-presence of PCB 153 resulted in an amplification of the $\mathrm{MeHg}$ effects, then it would be reasonable to expect that the profile of the combined exposure would approach that in the $\mathrm{MeHg} 2.0$ group (i.e. it would be shifted toward slower body growth, faster incisor eruption and poor performance in the forepaw suspension and air righting tests). A look at Table 2 shows that this was not the case.

If the presence of $\mathrm{MeHg}$ amplified the PCB 153 effects, then one might expect for the $\mathrm{MeHg}+\mathrm{PCB} 153$ progeny a significant delay in the pinna detachment, poor performance in the forepaw suspension test and possibly the air righting test. Such effect was not observed.

What was observed, was almost total ineffectiveness of the combined exposure in producing overt alterations in the pup development ${ }^{1}$. This suggests an antagonistic type of interaction between PCB 153 and MeHg. Besides, the fact

\footnotetext{
${ }_{1}$ The higher proportion of females in the progeny of the exposed group is intriguing. However, this was probably an accidental effect, as similar observations were not reported in any of the studies concerning the effects of PCB 153 and/or $\mathrm{MeHg}$ exposure.
} 
Table 2. Summary of the effects of perinatal exposure to MeHg or PCB 153, or MeHg + PCB 153 in the offspring

\begin{tabular}{|c|c|c|c|c|c|c|}
\hline \multirow[b]{3}{*}{ Endpoint measured } & \multicolumn{6}{|c|}{ Effect of exposure } \\
\hline & \multicolumn{3}{|c|}{ Males } & \multicolumn{3}{|c|}{ Females } \\
\hline & $\begin{array}{c}\mathrm{MeHg} \\
0.5 \mathrm{mg} / \mathrm{kg}\end{array}$ & $\begin{array}{c}\text { PCB } \\
5.0 \mathrm{mg} / \mathrm{kg}\end{array}$ & $\begin{array}{c}\mathrm{MeHg} \\
0.5 \mathrm{mg} / \mathrm{kg} \\
+ \\
\mathrm{PCB} \\
5.0 \mathrm{mg} / \mathrm{kg}\end{array}$ & $\begin{array}{c}\mathrm{MeHg} \\
0.5 \mathrm{mg} / \mathrm{kg}\end{array}$ & $\begin{array}{c}\text { PCB } \\
5.0 \mathrm{mg} / \mathrm{kg}\end{array}$ & $\begin{array}{c}\mathrm{MeHg} \\
0.5 \mathrm{mg} / \mathrm{kg} \\
+ \\
\mathrm{PCB} \\
5.0 \mathrm{mg} / \mathrm{kg}\end{array}$ \\
\hline Body weight & ns & $+(?)$ & ns & ns & $(+)$ & ns \\
\hline Pinna detachment & ns & $-(?)$ & ns & ns & $-(?)$ & ns \\
\hline Incisor eruption & $+(?)$ & $-(?)$ & ns & $(+)$ & $-(?)$ & $\mathrm{ns}$ \\
\hline Eye opening & $\mathrm{ns}$ & ns & ns & ns & ns & ns \\
\hline Negative geotaxis & $(+)$ & ns & $\mathrm{ns}$ & $(+)$ & $\mathrm{ns}$ & ns \\
\hline Forepaw suspension & ns & $(-)$ & ns & ns & ns & ns \\
\hline Air righting & ns & ns & ns & ns & ns & ns \\
\hline
\end{tabular}
$(-)$ - worse than controls.
$(+)$ - better than controls.
ns - difference not significant when compared to the control non-exposed group.
(?) - result questionable.

that neither the effect of $\mathrm{MeHg}$ nor those of PCB 153 were present in the progeny of the $\mathrm{MeHg}+\mathrm{PCB} 153$ group indicates that the antagonism is mutual.

It should be stressed, however, that making assumptions on the character of the MeHg and PCB 153 interaction in the present experiment is complicated by the nonlinearity - in some endpoints - of the dose-effect relationships. It concerns $\mathrm{MeHg}$ exposure: (better scores in negative geotaxis test were observed only in the low dose group) as well as the PCB 153 exposure. In this latter case the pinna detachment and incisor eruption were accelerated in the progeny of the low dose group but delayed in the progeny of the high dose group. (It cannot be excluded that, if the dose range and the number of PCB 153 doses were higher, similar bidirectionality could be observed in the effect on body weight). The above observations allow one to suspect that the doses of PCB 153 and $\mathrm{MeHg}$ in the present experiment were within the hormetic range [55].

\section{Summary and concluding remarks}

The data obtained in the present work provide no support for the assumption of a synergistic action of $\mathrm{MeHg}$ and PCB 153 on the development. This assumption received no support also in the already published parts of this study: that concerning the effect of the perinatal $\mathrm{MeHg}$ and PCB 153 exposure on the brain catecholamine content in adulthood [56], and that on the behavioural sensitivity to psychostimulants and susceptibility to psychostimulant-induced sensitisation [57]. In both cases the results suggested an antagonistic rather than synergistic type of interaction.

No support for synergistic MeHg and PCB 153 interaction was obtained in studies on the effect of perinatal exposure on brain cholinergic receptors[45,58], monoaminergic transmission [59], and glutamatergic transmission and learning [46]. Also other in vivo studies using behavioural endpoints: motoric functions [39,60], spatial memory functions [37], open-field behaviour [38] provided no proof of a synergistic or additive $\mathrm{PCB} / \mathrm{MeHg}$ interaction. The only results suggesting a synergistic type of $\mathrm{PCB}$ (PCB 153, 126) and $\mathrm{MeHg}$ interaction come from the Fisher et al. [61] study on mice with the use of the open-field test.

These results have been questioned, however, on the methodological grounds [62].

An evidence of synergistic interaction was obtained in an in vitro study. It showed that incubation of AtT20 cells (a 
pituitary cell line) with $\mathrm{MeHg}$ and PCB 153 or PCB 126, at moderately toxic doses, resulted in a higher number of apoptotic cells than that noted in conditions of separate exposures [63]. In another in vitro study on P 12 cells, however, with cell viability as the endpoint, it was found that, at some concentration combinations of MeHg and PCB 153 in the medium, the cell survivability was higher compared to that observed during separate exposures [64]. In a recent experiment with asynchronous exposures, the authors have shown that antagonistic interaction occurs when the $\mathrm{MeHg}$ exposure precedes the exposure to PCB153. Results of a reverse combination (PCB 153 preceding exposure to $\mathrm{MeHg}$ ) suggested an additive type of interaction [65]. Antagonistic interaction was also observed in some in vivo studies. Piedrafita et al. [46] have reported recently that whereas a separate perinatal exposure to $\mathrm{MeHg}$, PCB 153 or PCB 126 produced deficits in spatial learning and malfunction of the glutamate-NO pathway in the cerebellum in maturity, none of these effect were produced by a combined MeHg and PCB exposure. Antagonistic $\mathrm{MeHg} / \mathrm{PCB}$ (Aroclor 1254) interaction is also suggested by the behavioural data presented by Sugawara et al. [38]. Based on the reports cited above it may be thus concluded that the ineffectiveness of the combined, but not separate, perinatal exposure to $\mathrm{MeHg}$ and PCB 153 to affect early morphological and physical development in the present experiments, as well as some neurobehavioural function in maturity $[56,57]$ is not an experimental artefact.

\section{ACKNOWLEDGEMENTS}

The authors express their appreciation to Z. Pisarek, U. Dadziak and dr J. Piasecka-Zelga for their contribution to this project.

\section{REFERENCES}

1. Gochfeld M, Burger J. Good fish/bad fish: A composite benefit-risk by dose curve. Neurotoxicology 2005;26:511-20.

2. Sidhu KS. Health benefits and potential risk related to consumption of fish or fish oil. Regul Toxicol Pharmacol 2003;38: $336-44$.
3. Domingo JL. Omega-3 fatty acids and the benefits of fish consumption: Is all that glitters gold? Environment International 2007;33:993-8.

4. Takeuchi T. Human effects of methylmercury as an environmental neurotoxicant. In: Blum K, Manzo L. (Eds). Neurotoxicology. New York: Marcel Dekker; 1985. p. 345-67.

5. Sanfeliu C, Sebastia J, Cristofol R, Rodriguez-Farre E. Neurotoxicity of organomercurial compounds. Neurotoxicity Res 2003;5(4):283-306.

6. Castoldi AF, Coccini T, Manzo L. Neurotoxic and molecular effects of methylmercury in humans. Reviews on Environmental Health 2003;18:19-31.

7. Kalmijn S, Van Boxtel MP, Ocké M, Verschuren WM, Kromhout D, Launer LJ. Dietary intake of fatty acids and fish in relation to cognitive performance at middle age. Neurology 2004 Jan 27;62(2):275-80.

8. Breslow JL. $n$-3 fatty acids and cardiovascular disease. Am J Clin Nutr 2006;83 (6 Suppl):1477S-82S.

9. Van Gelder BM, Tijhuis M, Kalmijn S, Kromhout D. Fish consumption, $n-3$ fatty acids, and subsequent 5-y cognitive decline in elderly men: the Zutphen Elderly Study. Am J Clin Nutr 2007;85(4):1142-7.

10. Samieri C, Jutand MA, Féart C, Capuron L, Letenneur L, Barberger-Gateau P. Dietary patterns derived by hybrid clustering method in older people: association with cognition, mood, and self-rated health. J Am Diet Assoc 2008 Sep;108(9):1461-71.

11. Augood C, Chakravarthy U, Young I, Vioque J, De Jong PT, Bentham G, et al. Oily fish consumption, dietary docosahexaenoic acid and eicosapentaenoic acid intakes, and associations with neovascular age-related macular degeneration. Am J Clin Nutr 2008;88(2):398-406.

12. Turunen AW, Verkasalo PK, Kiviranta H, Pukkala E, Jula A, Männistö S, et al. Mortality in a cohort with high fish consumption. Int J Epidemiol 2008;37(5):1008-17.

13. Grandjean P, Landrigan PJ. Developmental neurotoxicity of industraial chemicals. Lancet 2006;368:2167-78.

14. Amin-Zaki L, Elhassani SB, Majeed MA, Clarkson TW, Doherty RA, Greenwood M. Intra-uterine methylmercury poisoning in Iraq. Pediatrics 1974;54(5):587-95.

15. Amin-Zaki L, Majeed MA, Elhassani SB, Clarkson TW, Greenwood MR, Doherty RA. Prenatal methylmercury 
poisoning. Clinical observations over five years. Am J Dis Child 1979;133:172-81.

16. Spurgeon A. Prenatal methylmercury exposure and developmental outcomes: Review of the evidence and discussion of future directions. Environ Health Perspect 2006;114(2): 307-12.

17. Grandjean P, Weihe P, White RF, Debes F, Araki S, Murata K, et al. Cognitive deficit in 7-year-old children with prenatal exposure to methylmercury. Neurotoxicol Teratol 1997;19:417-28.

18. Debes F, Budtz-Jørgensen E, Weihe P, White RF, Grandjean P. Impact of prenatal methylmercury exposure on neurobehavioral function at age 14 years. Neurotoxicol Teratol. 2006 Sep-Oct; 28(5):536-47.

19. Davidson PW, Myers GJ, Cox C, Axtell C, Shamlaye C, Sloane-Reeves J, et al. Effects of prenatal and postnatal methylmercury exposure from fish consumption on neurodevelopment at 66 months of age in the Seychelles Child Development Study. JAMA 1998;280(8):701-7.

20. Davidson PW, Myers GJ, Weiss B, Shamlaye CF, Cox C. Prenatal methyl mercury exposure from fish consumption and child development: a review of evidence and perspectives from the Seychelles Child Development Study. Neurotoxicology 2006;27:1106-9.

21. Myers GJ, Davidson PW, Cox Ch, Shamlaye CF, Palumbo D, Cernichari E, et al. Prenatal methylmercury exposure from ocean fish consumption in the Seychelles child development study. The Lancet 2003;361:1686-92.

22. Counter SA, Buchanan LH. Mercury exposure in children: a review. Toxicol Appl Pharmacol 2004;198:209-30.

23. Nakai K, Satoh H. Developmental neurotoxicity following prenatal exposures to methylmercury and PCBs in humans from epidemiological studies. Tohoku J Exp Med 2002;196(2): 89-98.

24. Mössner S, Ballschmiter K. Marine mammals as global pollution indicators for organochlorines. Chemosphere 1997;34 (5-7):1285-96.

25. Kleivane L, Skaare JU. Organochlorine contaminants in Northeast Atlantic minke whales (Balaenoptera acutorostrata). Environ Pollut 1998;101(2):231-9.

26. Carpenter DO. Polychlorinated biphenyls and human health. Int J Occup Med Environ Health 1998;11(4):291-303.
27. Carpenter DO. Polychlorinated biphenyls (PCBs): routes of exposure and effects on human health. Rev Environ Health 2006;21(1):1-23.

28. Faroon O, Jones D, de Rosa C. Effects of polychlorinated biphenyls on the nervous system. Toxicol Ind Health 2001;16 (7-8):305-33.

29. Seegal RF. Epidemiological and laboratory evidence of PCBinduced neurotoxicity. Crit Rev Toxicol 1996;26:709-16.

30. Boucher O, Muckle G, Bastien CH. Prenatal exposure to polychlorinated biphenyls: A neuropsychologic analysis. Environ Health Perspect 2009;117(1):7-16.

31. Grandjean P, Weihe P, Burse VW, Needham LL, Storr-Hansen E, Heinzow B, et al. Neurobehavioral deficits associated with PCB in 7-year-old children prenatally exposed to seafood neurotoxicants. Neurotoxicol Teratol 2001;23:305-17.

32. Bemis JC, Seegal RF. Polychlorinated biphenyls and methylmercury act synergistically to reduce rat brain dopamine content in vitro. Environ Health Perspect 1999;107:879-85.

33. Bemis JC, Seegal RF. Polychlorinated biphenyls and methylmercury alter intracellular calcium concentrations in rat cerebellar granule cells. Neurotoxicology 2000;21:1123-34.

34. Newland M Ch. Neurobehavioral toxicity of methylmercury and PCBs. Effects-profiles and sensitive populations. Environ Toxicol Pharm 2002;12:119-28.

35. Risher JF, de Rosa C, Murray HE, Jones D. Joint PCB-methylmercury exposures and neurobehavioral outcomes. Hum Ecol Risk Assess 2003;9:1003-10.

36. Stewart PW, Reihman J, Lonky EI, Darvill T, Pagano J. Cognitive developmant in preschool children prenatally exposed to PCBs and MeHg. Neurotoxicol Teratol 2003;25:11-22.

37. Widholm JJ, Villareal S, Seegal RF, Schantz SL. Spatial alternation deficits following developmental exposure to Aroclor 1254 and/or methylmercury in rats. Toxicol Sci 2004;82(2): $577-89$.

38. Sugawara N, Ohba T, Nakai K, Kakita A, Nakamura T, Suzuki K, et al. Effects of perinatal coexposure to methylmercury and polychlorinated biphenyls on neurobehavioral development in mice. Arch Toxicol 2008;82(6):387-97.

39. Roegge CS, Wang VC, Powers BE, Klintsova AY, Villareal S, Greenough WT, et al. Motor impairment in rats exposed to PCBs and methylmercury during early development. Toxicol Sci 2004;77(2):315-24. 
40. Longnecker MP, Wolff MS, Gladen BC, Brock JW, Grandjean P, Jacobson JL, et al. Comparison of polychlorinated biphenyl levels across studies of human neurodevelopment. Environ Health Perspect 2003;111(1):65-70.

41. Rossi AD, Ahlbom E, Ogren SO, Nicotera P, Ceccatelli S. Prenatal exposure to methylmercury alters locomotor activity of male but not female rats. Exp Brain Res 1997;117(3):428-36.

42. Cernichiari E, Brewer R, Myers GJ, Marsh DO, Lapham LW, Cox C, et al. Monitoring methylmercury during pregnancy: maternal hair predicts fetal brain exposure. Neurotoxicology 1995;16(4):705-10.

43. Overmann SR, Fox DA, Wooley DE. Neurobehavioral ontogeny of neonatallylead-exposed rats. I. Reflex development and somatic indices. Neurotoxicology 1979;1(1):125-47.

44. Winer BJ. Statistical principles in experimental design. New York: Mac Graw Hill Book Company; 1992.

45. Coccini T, Roda E, Castoldi AF, Goldoni M, Poli D, Bernocchi G, et al. Perinatal co-exposure to methylmercury and PCB153 or PCB126 in rats alters the cerebral cholinergic muscarinic receptors at weaning and puberty. Toxicology 2007;238:34-48.

46. Piedrafita B, Erceg S, Cauli O, Felipo V. Developmental exposure to polychlorinated biphenyls or methylmercury, but not to its combination, impairs the glutamate-nitric oxidecyclic gmp pathway and learning in 3-month-old rats. Neuroscience 2008;154:1408-16.

47. Vorhees Ch. Behavioral effects of prenatal methylmercury in rats: A parallel trial to the Collaborative Behavioral Teratology Study. Neurobehav Toxicol Teratol 1985;7:717-25.

48. Overmann SR, Kostas J, Wilson LR, Shain W, Bush B. Neurobehavioral and somatic effects of perinatal $P C B$ exposure in rats. Environ Res 1987;44:56-70.

49. Bowers WJ, Nakai JS, Chu I, Wade MG, Moir D, Yagminas A, et al. Early developmental neurotoxicity of a PCB/organochlorine mixture in rodents after gestational and lactational exposure. Toxicol Sci 2004;77: 51-62.

50. Nguon K, Baxter MG, Sajdel-Sulkowska EM.Perinatal exposure to polychlorinated biphenyls differentially affects cerebellar development and motor functions in male and female rat neonates. Cerebellum 2005;4(2):112-22.

51. Schantz S, Moshtaghian J, Ness DK. Spatial learning deficits in adult rats exposed to ortho-substituted $P C B$ congeners during gestation and lactation. Fundam Appl Toxicol 1995;26(1): 17-126.

52. Holene E, Nafstad I, Skaare JU, Sagvolden T. Behavioural hyperactivity in rats following postnatal exposure to sub-toxic doses of polychlorinated biphenyl congeners 153 and 126. Behav Brain Res 1998;94:213-24.

53. Holene E, Nafstad I, Skaare JU, Krogh H, Sagvolden T. Behavioural effects in female rats of postnatal exposure to subtoxic doses of polychlorinated biphenyl congener 153 Acta Pediatr Suppl 1999;429:55-63.

54. Kobayashi K, Miyagawa M, Wang RS, Suda M, Sekiguchi S, Honma T. Effects of in utero exposure to 2,2',4,4',5,5'-hexachlorobiphenyl (PCB 153) on somatic growth and endocrine status in rat offspring. Congenit Anom (Kyoto). 2008;48(4):151-7.

55. Calabrese EJ. Hormesis: why it is important to toxicology and toxicologists. Environ Toxicol Chem 2008;27(7):1451-74.

56. Świercz R, Grzelińska Z, Majcherek W, Wiaderna D, Lutz P, Sitarek K, et al. Brain catecholamine concentrations in adult rats exposed perinatally to methylmercury and/or PCB 153. Polish J of Environ Stud 2008;17:(4):587-96.

57. Lutz P, Wiaderna D, Gralewicz S, Świercz R. Effects of Perinatal MeHg and/or 2,2',4,4',5,5'-hexachlorobiphenyl (PCB153) Exposure on Adult Vulnerability to Amphetamine in the Rat. Polish J Environ Stud 2008;17:557-67.

58. Coccini T, Randine G, Castoldi AF, Grandjean P, Ostendorp G, Heinzow B, et al. Effects of developmental co-exposure to methylmercury and 2,2,4,4,5,5'-hexachlorobiphenyl (PCB153) on cholinergic muscarinic receptors in rat brain. Neurotoxicology 2006;27(4):468-77.

59. Castoldi AF, Blandini F, Randine G, Samuele A, Manzo L, Coccini T. Brain monoaminergic neurotransmission parameters in weanling rats after perinatal exposure to methylmercury and 2,2',4,4',5,5'-hexachlorobiphenyl (PCB153). Brain Res 2006;1112(1):91-8.

60. Roegge CS, Morris JR, Villareal S, Wang VC, Powers BE, Klintsova AY, et al. Purkinje cell and cerebellar effects following developmental exposure to PCBs and/or MeHg. Neurotoxicol Teratol 2006;28(1):74-85.

61. Fischer C, Fredriksson A, Eriksson P. Neonatal co-exposure to low doses of an ortho-PCB (PCB 153) and methyl mercury exacerbate defective developmental neurobehavior in mice. Toxicology 2008;244(2-3):157-65. 
62. Hardy ML. Developmental neurotoxicity in neonatal mice following coexposure to PCB 153 and methyl mercury: interaction or false positive? Toxicology 2008;248:160-1.

63. Johansson C, Tofighi R, Tamm C, Goldoni M, Mutti A, Ceccatelli S. Cell death mechanisms in AtT20 pituitary cells exposed to polychlorinated biphenyls (PCB 126 and PCB 153) and methylmercury. Toxicol Lett 2006;167(3):183-90.

64. Vettori MV, Goldoni M, Caglieri A, Poli D, Folesani G, Ceccatelli S, et al. Antagonistic effects of methyl-mercury and
PCB153 on PC12 cells after a combined and simultaneous exposure. Food Chem Toxicol 2006;44(9):1505-12.

65. Goldoni M, Caglieri A, Poli D, Vettori MV, Ceccatelli S, Mutti A. Methylmercury at low doses modulates the toxicity of PCB153 on PC12 neuronal cell line in asynchronous combination experiments. Food Chem Toxicol 2008;46(2):808-11. 